\title{
BUSINESS CLIENT SEGMENTATION IN BANKING USING SELF-ORGANIZING MAPS
}

Mirjana Pejić Bach, Sandro Juković, Ksenija Dumičić, Nataša Šarlija*

\begin{abstract}
Segmentation in banking for the business client market is traditionally based on size measured in terms of income and the number of employees, and on statistical clustering methods (e.g. hierarchical clustering, $k$-means). The goal of the paper is to demonstrate that self-organizing maps (SOM) effectively extend the pool of possible criteria for segmentation of the business client market with more relevant criteria, including behavioral, demographic, personal, operational, situational, and cross-selling products. In order to attain the goal of the paper, the dataset on business clients of several banks in Croatia, which, besides size, incorporates a number of different criteria, is analyzed using the SOM-Ward clustering algorithm of Viscovery SOMine software. The SOM-Ward algorithm extracted three segments that differ with respect to the attributes of foreign trade operations (import/export), annual income, origin of capital, important bank selection criteria, views on the loan selection and the industry. The analyzed segments can be used by banks for deciding on the direction of further marketing activities.
\end{abstract}

Keywords: self-organizing maps, segmentation, banking, neural networks, data mining

JEL classification: $M 31, G 21$

\section{INTRODUCTION}

Client segmentation is the process of dividing markets into homogenous groups of consumers. The idea is to create customized marketing strategies for selected segments in order to satisfy clients' needs better. Banks can offer customized products to those market segments in order to increase their profitability (Anderson, Cox and Fulcher, 1976; Laroche, Rosenblatt and Manning, 1986; Garland, 2005). In applying marketing strategy in financial institutions, the provider of financial services makes a distinction among various market segments. Services, the marketing mix and the communication mix are tailored to one or more selected segments (Denton and Chan, 1991). Market segmentation can be done according to various criteria when it is applied to an individual client market, e.g. geographic, demographic, psychographic and behavioural (Kotler et al., 2001). However, the criterion most commonly used by financial institutions in the business client market is size measured in terms of income and the number of employees (Piercy, 1992; Meadows and Dibb, 1998).

Various methods have been used for market segmentation, such as different clustering methods, fuzzy methods, regression methods, neural networks, self-organizing maps, and others (e.g. Wedel and Kamakura, 2003; Chan, Kwong and $\mathrm{Hu}, 2012$; Hanafizadeh and Mirzazadeh, 2011). Classical

Mirjana Pejić Bach
Full professor
Faculty of Economics \& Business, University of Zagreb
E-mail: mpejic@efzg.hr
Sandro Juković
IT Solutions Manager
Erste\&Steiermärkische Bank
E-mail: sandro.jukovic@gmail.com
Ksenija Dumičić
Full professor
Faculty of Economics \& Business, University of Zagreb
E-mail: kdumicic@efzg.hr
Nataša Šarlija
Full professor
Faculty of Economics in Osijek, University of Osijek
E-mail: natasa@efos.hr


cluster analysis methods (e.g. k-means, hierarchical cluster analysis) give a remarkable level of precision (Mingoti and Lima, 2006). However, the problem is that they lack the possibility to automatically determine the number of resulting clusters, and the number of clusters depends on prior understanding of the dataset. Consequently, analyzing complex databases would not be easy. Therefore, the need for automatic characterizing is obvious. The self-organizing maps (SOM) method is considered to be a successful supplemental method for classical clustering methods. Kuo, Ho and $\mathrm{Hu}$ (2002) compared three clustering methods for segmentation in the $3 \mathrm{C}$ (computer, communication, consumer electronic) market: the conventional two-stage method, the SOM and the two-stage method as a combination of SOM and k-means. They showed that, compared to the conventional two-stage method, the two-stage method combining SOM and k-means gives better results on the basis of theoretical and practical evaluations. Hung and Tsai (2008) developed a hierarchical SOM model for market segmentation of multimedia demand in Taiwan. They showed that the hierarchical SOM model provided better interpretation of the results than the traditional statistical clustering analysis and the growing hierarchical self-organizing map. Schmitt and Deboeck (1998) conducted a study using the results of a consumer survey in Beijing and Shanghai that illustrated the efficacy of self-organizing maps. Mangiameli, Chen, and West (1996) compared the performance of the SOM and the hierarchical clustering method using 252 datasets with various levels of imperfection, and showed that the SOM method outperformed the hierarchical clustering method.

The aim of this paper is to create and explain business client segmentation in the Croatian banking industry using the SOM method. The motivation for this research is threefold. First, to our knowledge, there are no papers describing business client segmentation in the banking industry in Croatia. Second, banks in Croatia use traditional segmentation of the corporate sector, which can sometimes blur the actual situation. Therefore, data mining, such as cluster analysis, can find segments that have previously been disregarded. Since the dataset for this research is complex and has never been analyzed before, we decided to implement the SOM method. Third, the criterion for banking segmentation is traditionally size measured in terms of income and the number of employees (Piercy, 1992; Meadows and Dibb, 1998), and in this research we have used many other criteria, such as decision makers' characteristics, an operating criterion, and a supply management criterion. In this research we had a complex database consisting of many variables, which is the reason why the SOM method is chosen for the analysis.

The paper's composition is the following. First, an overview of previous research is given. The second part of the paper describes the methodology of the paper, encompassing research methods and the data used in the research. The third part of the paper presents the cluster analysis resulting in the business customer segmentation. The discussion and the concluding part of the paper present the profile of each cluster and summarize the results of the analysis.

\section{LITERATURE REVIEW}

Segmentation in banking is one of the most important business decisions, since the practice of designing special groups or baskets of products for special groups of clients is at the root of the modern approach to banking. The two main groups of clients in banking are individual clients (Ekinci, Uray and Ulengin, 2014) and business clients (Turnbull and Gibbs, 1987). Most of the research in segmentation in banking is oriented towards the retail market. Mäenpää (2006) provides the framework for developing market segments for consumers based on their perceptions of the Internet banking service, with the goal of detecting possible improvements to the banking application. Machauer and Morgner (2001) present segmentation of individual banking clients using a mixture of customer attitudes and perceptions of bank service benefits. On the other hand, our research is oriented towards the business client segmentation in banking.

The traditional approach to business segmentation in banking for the business client market is mainly based on the criterion of size, measured in terms of income and the number of employees (Piercy, 1992; Meadows and Dibb, 1998). Additionally, other financial criteria include a company's loan exposure and the ownership of a company (Sponer, 2012). In addition, Edris (1997) used multiple discriminant analysis and revealed that in Kuwait the ownership of a corporation (Kuwaiti, non-Kuwaiti and joint business corporations) was related to the selection of a bank. The business intelligence approach regards data as a company's assets (Watson and Wixom, 2007). Hence, our research is based on the proposition that business client data that encompass business client behavior, such as decision maker characteristics, business client characteristics, an operating criterion, a supply management criterion and a situational criterion should also be used as a basis for business decision-making, in this case segmentation. The rationale for selecting the abovementioned criteria will be presented. In all business situations, including commercial and consumer markets, it will ultimately be individuals who make decisions, but a company's policy limits them in decisionmaking, which stresses the importance of decision maker preferences (Shocker et al., 1991). Business client characteristics refer to the company size (Piercy, 1992; Meadows and Dibb, 1998), industry (Athanassopoulos, 2000), location (Venkatesh, 2011), and the international orientation of the company (Agarwal, Malhotra and Bolton, 2010). The operating criterion facilitates segmentation based on the specific behaviour of the client, which is reflected in specific transactions conducted by the client (e.g. credit card usage) or planned transactions (e.g. planned credit card usage), or attitude towards the most important operating service (Patsiotis, Hughes and Webber, 2012). Supply chain management determines the procurement organization of the client and its rules when deciding whether to take a familiar, a national or the cheapest vendor, etc. The supply chain management criterion describes a client's affinity towards price and service quality (Chen and Bell, 2012). Finally, situational criterion elements do not have a permanent character and push companies to understand a client more deeply (Kim 
and Grunig, 2011). In our research, they include the major bank where most of the services are used, and the level of satisfaction with the current major bank.

The cluster analysis is the basic method of knowledge discovery in databases that can be used for market segmentation (Mäenpää, 2006). Traditional clustering methods are hierarchical methods and k-means. The aim of these methods is the detection of global data structures. In this method the target attribute is not predefined, so there is no difference among the attributes' importance. Clustering methods fall into a group of "unattended" methods. Self-organizing maps (SOM) are the two-layered artificial neural networks which were initially designed to conduct the tasks of clustering, data visualization and abstraction (Han and Kamber, 2006, pp. 434). SOM has been used for market segmentation in tourism (Kun et al., 2002) as well as in various other fields of market segmentation, such as telecommunication (Kiang, et al., 2006), on-line game markets (Lee et al., 2004), on-line shopping (Vellido et al., 1999), tourism (Bloom, 2004), computer, communication and consumer electronic markets (Kuo, Ho and Hu, 2002), and multimedia products (Hung and Tsai, 2008). Our research explores the possible usage of SOM methods for business client segmentation in banking.

To summarize, further research is needed in the field of business client segmentation in banking. In order to expand knowledge on business client segmentation in banking, new research is needed that would, in addition to size measured in terms of turnover and the number of employees, use a more extensive set of criteria, including decision maker characteristics, business client characteristics, an operating criterion, a supply management criterion and a situational criterion. In addition, by using the SOM method in our research, we test the applicability of this novel approach to the field of business client segmentation in banking.

\section{METHODOLOGY}

\section{Self-organizing maps (SOM)}

Self-organizing maps (SOM) are based on the concept of neural networks. The neural network is a model of a biological neural network of the human nervous system, a set of parallel interconnected neurons that are organized in layers (Jagric and Jagric, 2011). The main feature of artificial neural networks as well as SOM is the property of learning from the data that are entered in the network input layer. Thus a complex interaction of the analyzed data can be modelled without having to know the nature of the phenomena the data describes. In other words, it is not necessary to create an algorithm that will analyze the data, but through training the neural network learns how to analyze data on its own. Besides the learning capacity of the SOM method, two other important features of this method have to be mentioned (Bigus, 1996). The first is the dimensionality reduction of the data and the second is the placement of similar data to neighbouring nodes on the resulting map. The dimensionality reduction facilitates easier understanding of the attribute interrelationship between the input data, while grouping similar data together enables data clustering. Thus, it is possible to apply this method in the field of market segmentation. In fact, any connection between neurons of the input-output layer has its corresponding weight. In practice, neural networks, among other things, are used in the financial services industry (Kumar and Ravi, 2007).

In humans, various sensory stimuli are neurologically mapped in the brain so that the spatial relationship between stimuli of certain parts of the brain corresponds to the spatial relationship between neurons organized in a two-dimensional map (Kohonen, 1995). Consequently, the location of points on the map reflects the relative similarity of points in a multidimensional space, i.e. the more two datasets are similar to each other, the closer they will be on the resulting two-dimensional map. Accordingly, the SOM's primary function is to display multidimensional data from the inputs of the network in the two-dimensional map, while retaining the relationships among data (Kiang, 2001).

The Ward Clustering Method is a part of the Viscovery SOMine data mining software tool, which encompasses the SOM-Ward algorithm that is used for the data analysis in this paper. The Classical Ward method belongs to hierarchical agglomeration algorithms which have the following characteristics: they start with the clustering process where every cluster represents one cluster, and in each of the clustering steps the two clusters that have a minimal distance are joined. The minimal distance is called the Distance Niveau.

The SOM-Ward algorithm is a so-called hybrid algorithm which was developed on the grounds of the soft computing paradigm, which is primarily based on the usage of various intelligent methods and algorithms, as opposed to the hard computing paradigm. In SOMine, the distance matrix is initialized with respect to the number of data records which are represented by nodes on the output map. The nodes with many corresponding data records have a higher impact in comparison with the nodes with fewer connections.

\section{Sample description}

In order to conduct segmentation using the SOM-Ward algorithm, a questionnaire survey approach was utilized to collect data from Croatian firms. Questionnaires were distributed among Croatian micro ( $<10$ employees), small (11-49 employees), medium (50-249 employees) and large (250+ employees) firms. Business clients that participated in the research were selected randomly from the Croatian Company Directory, available at the website of the Croatian Chamber of Commerce. The stratified sample approach was used in order to capture more large and medium sized firms, which are important for banks because, in comparison to small and micro firms, they conduct larger financial transactions. Data for this research were collected through a questionnaire answered by 850 Croatian firms.

Table 1 visibly specifies that, according to the sample size, the structure of firms that participated in the survey differs to a large extent from the structure of firms in Croatia as a whole. Our sample contained $38.83 \%$ of micro firms, while in Croatia micro firms comprise $92 \%$ of the total population. 
Table 1: Comparison of firms that participated in the survey and population characteristics

\begin{tabular}{|c|c|c|c|c|c|}
\hline \multirow{2}{*}{ Firm size } & \multicolumn{2}{|c|}{ Sample } & \multicolumn{2}{|c|}{ Croatia } & \multirow{2}{*}{$\begin{array}{l}\text { Chi-square } \\
\text { (p-value) }\end{array}$} \\
\hline & Number of firms & Structure in \% & Number of firms & Structure in \% & \\
\hline Micro firms (<10 employees) & 304 & $35.8 \%$ & 152251 & $92.0 \%$ & \multirow{5}{*}{$\begin{array}{c}63.656 \\
\left(0.000^{* *}\right)\end{array}$} \\
\hline Small firms (10- 49 employees) & 263 & $30.9 \%$ & 10757 & $6.5 \%$ & \\
\hline Medium firms (50-249 employees) & 182 & $21.4 \%$ & 1986 & $1.2 \%$ & \\
\hline Large firms (250+ employees) & 101 & $11.9 \%$ & 496 & $0.3 \%$ & \\
\hline Total & 850 & $100.0 \%$ & 165490 & $100.0 \%$ & \\
\hline
\end{tabular}

** statistically significant at $1 \%$

Source: Authors' calculation

Table 2: Segmentation criteria used in the research

\begin{tabular}{|c|c|}
\hline $\begin{array}{l}\text { Segmentation } \\
\text { criterion }\end{array}$ & Variables describing the criterion (type of variable) \\
\hline $\begin{array}{l}\text { Decision maker } \\
\text { preferences }\end{array}$ & $\begin{array}{l}\text { (1) the importance of selecting a bank providing services for clients (Likert 1-5) } \\
\text { (2) client rating of the best bank in Croatia (Likert 1-5) }\end{array}$ \\
\hline $\begin{array}{l}\text { Business client } \\
\text { characteristics }\end{array}$ & $\begin{array}{l}\text { (1) total number of employees (numeric) } \\
\text { (2) increase / decrease in revenues compared to the previous year (numeric) } \\
\text { (3) total income in the previous year (numeric) } \\
\text { (4) plans related to the number of employees (nominal) } \\
\text { (5) main business activity (nominal) } \\
\text { (6) legal form of the company (nominal) } \\
\text { (7) percentage of import and export in annual sales (numeric) } \\
\text { (8) ownership form of the company and the capital origin (nominal) } \\
\text { (9) the financial position of the company (nominal) } \\
\text { (10) method of wage payment (nominal) } \\
\text { (11) headquarters of the company and the year of establishment (nominal) }\end{array}$ \\
\hline Operating criterion & $\begin{array}{l}\text { (1) the most important reasons which affect the selection of a bank for a loan request (Likert 1-5) } \\
\text { (2) credit cards used by a client (binomial } 0-1 \text { ) } \\
\text { (3) credit cards which a company is planning to use (binomial } 0-1 \text { ) }\end{array}$ \\
\hline $\begin{array}{l}\text { Supply management } \\
\text { approach criterion }\end{array}$ & $\begin{array}{l}\text { (1) the three most important characteristics of a bank (e.g. security and stability, commissions } \\
\text { and fees, keeping up with promises) (Likert 1-5) } \\
\text { (2) the three most important characteristics of bank services (e.g. a wide spectrum of services, } \\
\text { quality and price ratio and promptness in solving requests) (Likert 1-5) }\end{array}$ \\
\hline Situational criterion & $\begin{array}{l}\text { (1) the major bank where most of the services are used (binomial 0-1) } \\
\text { (2) level of satisfaction with the current major bank (Likert 1-5) }\end{array}$ \\
\hline
\end{tabular}

Source: Authors

On the other hand, our sample contained $20.58 \%$ medium-sized firms, and the total Croatian population of firms contains only $1.20 \%$ medium-sized firms. Larger firms are also overrepresented in our sample. The chi-square test proved that these differences are statistically significant at $1 \%\left(\chi^{2}=63.656, p\right.$-value $\left.=0.000\right)$. Hence, the overpresence of large, medium and small firms, and underpresence of micro firms in our sample should be taken into account when considering the implications of the results of the research. However, such an approach was chosen taking into account that micro firms, although great in number, generate a smaller number and amount of financial transactions. On the other hand, medium and large firms, although small in number, generate a larger number and amount of financial transactions.

\section{Research instrument}

The literature review presented in the paper contains the rationale for selecting the segmentation criteria used for this research: decision maker characteristics, business client characteristics, an operating criterion, a supply management criterion and a situational criterion. The questionnaire 
for this research is developed based on the criteria described in the literature review section (Table 2). There were three types of questions: (1) Likert scales from 1 to $5,(2)$ questions with predefined answers (nominal variables), and (3) numeric variables.

\section{Statistical analysis}

The SOM-Ward algorithm implemented in Viscovery SOMine software was used in order to segment business customers. The SOM-Ward algorithm extracted three clusters, presented on a resulting map with only the main criteria used for a short description.

In analyzing and interpreting clusters, we first described each cluster according to all segmentation criteria. Second, we compared clusters descriptively. Finally, we applied the F-test for testing differences in mean values between clusters and chi-square for testing the association between clusters and different criteria.

\section{RESULTS OF BUSINESS CUSTOMER SEGMENTATION}

Figure 1 visually represents the identified clusters of business clients in banking, as well as presents the structure of the total sample according to clusters. Cluster 1 contains $50 \%$, Cluster 2 contains $36 \%$ and Cluster 3 only $14 \%$ of the total sample.

In analyzing and interpreting clusters it is very useful to compare clusters according to the segmentation criteria. This analysis serves as a basis for creating marketing
Figure 1: Identified clusters of business clients in banking

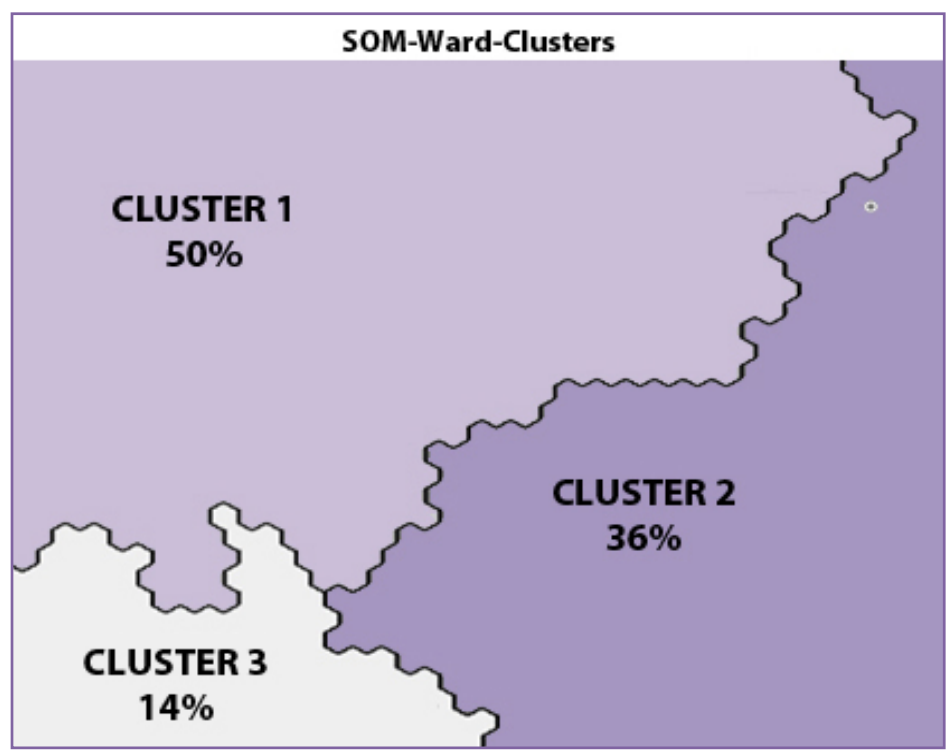

Source: Authors' calculation

strategies for each cluster. In Table 3 clusters are compared according to decision maker preferences. The percentages in the table present percentages of the companies which belong to a specific cluster and which have chosen certain criteria. For example $53.1 \%$ of companies in Cluster 1 think that selecting a bank is of very high importance. It can be noticed that in all of the three clusters the importance of selection on the basis of services provided by a bank is very high, although in the third cluster that percentage is the highest and in the second the lowest. As for the ranking of the best banks, bank $A$ is most common in the second

Table 3: Clusters according to the importance of selecting a bank providing services to clients, and to the clients' rating of the best bank in Croatia (\% of firms in the cluster)

\begin{tabular}{|c|c|c|c|c|c|}
\hline & Cluster 1 & Cluster 2 & Cluster 3 & Total & $\begin{array}{c}\text { Chi-square } \\
\text { (p-value) }\end{array}$ \\
\hline \multicolumn{6}{|c|}{ The importance of selecting a bank providing services for clients } \\
\hline Very high importance & $51.3 \%$ & $45.1 \%$ & $53.4 \%$ & $49.4 \%$ & \multirow{6}{*}{$\begin{array}{c}23.610 \\
\left(0.009^{* *}\right)\end{array}$} \\
\hline High importance & $31.7 \%$ & $34.0 \%$ & $28.8 \%$ & $32.1 \%$ & \\
\hline Medium importance & $7 \%$ & $6 \%$ & $7 \%$ & $6.6 \%$ & \\
\hline Low importance & $0 \%$ & $4 \%$ & $2 \%$ & $1.5 \%$ & \\
\hline Not important & $0 \%$ & $2 \%$ & $0 \%$ & $.7 \%$ & \\
\hline No answer & $9.9 \%$ & $9.5 \%$ & $9.3 \%$ & $9.7 \%$ & \\
\hline \multicolumn{6}{|c|}{ Clients' rating of the best bank in Croatia } \\
\hline Bank A & $23.2 \%$ & $32.7 \%$ & $25.4 \%$ & $26.9 \%$ & \multirow{7}{*}{$\begin{array}{c}116.301 \\
\left(0.000^{* *}\right)\end{array}$} \\
\hline Bank B & $16.8 \%$ & $19.6 \%$ & $24.6 \%$ & $18.9 \%$ & \\
\hline Bank C & $19.9 \%$ & $12.7 \%$ & $10.2 \%$ & $15.9 \%$ & \\
\hline Bank D & $5.7 \%$ & $4.9 \%$ & $6.8 \%$ & $5.5 \%$ & \\
\hline Other banks & $15.30 \%$ & $11.40 \%$ & $15.20 \%$ & $14.00 \%$ & \\
\hline There is no best bank & $5.40 \%$ & $3.30 \%$ & $5.10 \%$ & $4.60 \%$ & \\
\hline No answer & $13.70 \%$ & $15.40 \%$ & $12.70 \%$ & $14.20 \%$ & \\
\hline
\end{tabular}

** statistically significant at $1 \%$; statistically significant at $5 \%$

Source: Authors' calculation 
cluster, banks B and C are also highly represented in all clusters. Chi-squares show significant associations between clusters and the importance of selecting a bank providing services for customers $\left(\chi^{2}=23.610, p=0.009\right)$ as well as associations with customer ratings of the best bank $\left(\chi^{2}=116.301\right.$, $\mathrm{p}<0.000$ ). This means that companies in clusters differ according to decision makers' characteristics.

In Table 4 clusters are compared according to the average number of employees, and the average $\%$ of import and export in annual sales. The F-test revealed that there is no statistically significant difference in clusters' average numbers of employees $(F=1.711$, $p$-value $=0.181)$. As for import and export, Cluster 1 includes companies with the highest average import and export, and Cluster 2 with the lowest. In addition, the clusters have an average $\%$ of import in annual sales and an average \% of export in annual sales that are statistically significant at the $1 \%$ probability level.

Table 5 presents the business customer characteristics of the clusters. The percentages in the table present percentages of the companies which belong to a specific cluster. It can be noticed that clusters differ significantly according to the industry, total revenue, change of revenue compared to previous year, origin of capital and ownership, but not according to plans for employment $\left(\chi^{2}=11.591, p=0.072\right)$. Furthermore, in each cluster most business customers are from trade. Domestic capital is well represented in all clusters, and the most in the third cluster, while most foreign capital can be found in the first cluster. SMEs are the most represented in Cluster 2.

Table 4: Clusters according to the average numbers of employees, and average $\%$ of import and export in annual sales

\begin{tabular}{|l|c|c|c|c|c|}
\hline & Cluster 1 & Cluster 2 & Cluster 3 & Total & $\begin{array}{c}\text { F-testC } \\
(p \text {-value })\end{array}$ \\
\hline Average number of employees & 281.1 & 135.2 & 145.2 & 209.5 & $\begin{array}{c}1.711 \\
(0.181)\end{array}$ \\
\hline Average \% of import in annual sales & $29.6 \%$ & $10.9 \%$ & $22.1 \%$ & 21.8 & $\begin{array}{c}36.107 \\
\left(0.000^{* *}\right)\end{array}$ \\
\hline Average \% of export in annual sales & $16.1 \%$ & $6.9 \%$ & $9.9 \%$ & 11.9 & $\begin{array}{c}15.255 \\
\left(0.000^{* *}\right)\end{array}$ \\
\hline
\end{tabular}

** statistically significant at $1 \%$

Source: Authors' calculation

Table 5: Clusters according to the structure of firms based on business client characteristics (\% of firms in the cluster)

\begin{tabular}{|c|c|c|c|c|c|}
\hline & Cluster 1 & Cluster 2 & Cluster 3 & Total & $\begin{array}{c}\text { Chi-square } \\
\text { (p-value) }\end{array}$ \\
\hline \multicolumn{6}{|c|}{ Industry } \\
\hline Trade & $39.0 \%$ & $33.7 \%$ & $35.6 \%$ & $36.6 \%$ & \multirow{9}{*}{$\begin{array}{c}79.641 \\
\left(0.000^{* *}\right)\end{array}$} \\
\hline Production or mining & $24.8 \%$ & $12.7 \%$ & $11.0 \%$ & $18.5 \%$ & \\
\hline Construction & $5.4 \%$ & $8.2 \%$ & $12.7 \%$ & $7.4 \%$ & \\
\hline Tourism: hotels \& restaurants & $1.9 \%$ & $6.5 \%$ & $2.5 \%$ & $3.7 \%$ & \\
\hline Financial and other services & $2.1 \%$ & $6.5 \%$ & $1.7 \%$ & $3.7 \%$ & \\
\hline Transport and communications & $2.6 \%$ & $2.6 \%$ & $3.4 \%$ & $2.7 \%$ & \\
\hline Community services & $1.9 \%$ & $1.3 \%$ & $3.4 \%$ & $1.9 \%$ & \\
\hline Agriculture or fishing & $0.9 \%$ & $2.3 \%$ & $3.4 \%$ & $1.8 \%$ & \\
\hline Other & $21.4 \%$ & $26.2 \%$ & $26.3 \%$ & $23.7 \%$ & \\
\hline \multicolumn{6}{|c|}{ Total revenue in previous year } \\
\hline Up to 0.5 million EUR & $11.1 \%$ & $54.9 \%$ & $22.0 \%$ & $28.5 \%$ & \multirow{11}{*}{$\begin{array}{c}215.449 \\
\left(0.000^{* *}\right)\end{array}$} \\
\hline From 0.5 to 1 million EUR & $6.6 \%$ & $7.5 \%$ & $11.0 \%$ & $7.6 \%$ & \\
\hline From 1 to 1.5 million EUR & $4.7 \%$ & $3.6 \%$ & $3.4 \%$ & $4.1 \%$ & \\
\hline From 1.5 to 2 million EUR & $7.1 \%$ & $3.9 \%$ & $6.8 \%$ & $5.9 \%$ & \\
\hline From 2 to 5 million EUR & $19.9 \%$ & $8.5 \%$ & $17.8 \%$ & $15.5 \%$ & \\
\hline From 5 to 8 million EUR & $10.6 \%$ & $3.9 \%$ & $15.3 \%$ & $8.9 \%$ & \\
\hline From 8 to 10 million EUR & $5.4 \%$ & $2.0 \%$ & $3.4 \%$ & $3.9 \%$ & \\
\hline From 10 to 50 million EUR & $14.4 \%$ & $2.3 \%$ & $11.0 \%$ & $9.6 \%$ & \\
\hline 50 and more million EUR & $5.9 \%$ & $0.7 \%$ & & $3.2 \%$ & \\
\hline Don't know & $5.2 \%$ & $2.9 \%$ & $2.5 \%$ & $4.0 \%$ & \\
\hline Refuse to answer & $9.0 \%$ & $9.8 \%$ & $6.8 \%$ & $9.0 \%$ & \\
\hline
\end{tabular}




\begin{tabular}{|c|c|c|c|c|c|}
\hline \multicolumn{6}{|c|}{ Change of revenue compared to previous year } \\
\hline $\begin{array}{l}\text { Increase of revenue compared to } \\
\text { previous year }\end{array}$ & $69.7 \%$ & $54.2 \%$ & $72.0 \%$ & $64.5 \%$ & \multirow[t]{4}{*}{$\begin{array}{c}24.263 \\
\left(0.000^{* *}\right)\end{array}$} \\
\hline Revenue on the same level & $18.7 \%$ & $31.0 \%$ & $19.5 \%$ & $23.3 \%$ & \\
\hline Decrease & $10.4 \%$ & $13.1 \%$ & $8.5 \%$ & $11.1 \%$ & \\
\hline No answer & $1.2 \%$ & $1.6 \%$ & & $1.2 \%$ & \\
\hline \multicolumn{6}{|c|}{ Plans for employment in the next year } \\
\hline Retain all the employees & $41.6 \%$ & $48.7 \%$ & $44.9 \%$ & $44.6 \%$ & \multirow{4}{*}{$\begin{array}{r}11.591 \\
(0.072)\end{array}$} \\
\hline Employ new workers & $48.9 \%$ & $39.5 \%$ & $39.8 \%$ & $44.3 \%$ & \\
\hline No answer & $5.9 \%$ & $8.2 \%$ & $7.6 \%$ & $7.0 \%$ & \\
\hline Lay off employees & $3.5 \%$ & $3.6 \%$ & $7.6 \%$ & $4.1 \%$ & \\
\hline \multicolumn{6}{|c|}{ Origin of the capital } \\
\hline Domestic & $80.9 \%$ & $94.1 \%$ & $97.5 \%$ & $88.0 \%$ & \multirow{4}{*}{$\begin{array}{c}57.361 \\
\left(0.000^{* *}\right)\end{array}$} \\
\hline Foreign & $10.2 \%$ & $.3 \%$ & $1.7 \%$ & $5.4 \%$ & \\
\hline Mixed (domestic \& foreign) & $9.0 \%$ & $4.6 \%$ & $.8 \%$ & $6.3 \%$ & \\
\hline No answer & & $1.0 \%$ & & $.4 \%$ & \\
\hline \multicolumn{6}{|c|}{ Belonging to the group } \\
\hline Independent company & $61.2 \%$ & $55.6 \%$ & $70.3 \%$ & $60.4 \%$ & \multirow{5}{*}{$\begin{array}{r}103.383 \\
\left(0.000^{* *}\right)\end{array}$} \\
\hline SME & $9.9 \%$ & $35.3 \%$ & $13.6 \%$ & $19.6 \%$ & \\
\hline Owned by another company & $14.4 \%$ & $6.5 \%$ & $9.3 \%$ & $10.9 \%$ & \\
\hline Company owns other companies & $13.7 \%$ & $2.3 \%$ & $5.9 \%$ & $8.5 \%$ & \\
\hline No answer & $0.8 \%$ & $0.3 \%$ & $0.9 \%$ & $0.6 \%$ & \\
\hline
\end{tabular}

** statistically significant at 1\%; ${ }^{*}$ statistically significant at $5 \%$

Source: Authors' calculation

In Table 6 clusters are compared according to operating criteria. The interest rate is the most important criterion in the first and the second cluster while the speed and simplicity of procedures are the most important criteria in the third cluster. Chi-square results show a significant association between clusters and criteria for a loan request $\left(\chi^{2}=231.032\right.$, $\mathrm{p}<0.000$ ), which means that companies in clusters differ according to important criteria for a loan request.

Table 6: Clusters according to operating criteria (\% of firms in the cluster)

\begin{tabular}{|c|c|c|c|c|c|}
\hline & Cluster 1 & Cluster 2 & Cluster 3 & Total & $\begin{array}{c}\text { Chi-square } \\
\text { (p-value) }\end{array}$ \\
\hline \multicolumn{6}{|c|}{ Important criteria which affect the selection of a bank for a loan request } \\
\hline Interest rate & $65.5 \%$ & $51.3 \%$ & $3.4 \%$ & $51.7 \%$ & \multirow{12}{*}{$\begin{array}{c}231.032 \\
\left(0.000^{* *}\right)\end{array}$} \\
\hline Speed of loan approval & $13.0 \%$ & $12.1 \%$ & $28.0 \%$ & $14.8 \%$ & \\
\hline Knowing people at the bank & $0.2 \%$ & & & $0.1 \%$ & \\
\hline Repayment & $3.1 \%$ & $4.9 \%$ & $3.4 \%$ & $3.8 \%$ & \\
\hline Fees & $0.5 \%$ & & $1.7 \%$ & $0.5 \%$ & \\
\hline Simplicity of procedures & $9.9 \%$ & $10.1 \%$ & $24.6 \%$ & $12.0 \%$ & \\
\hline Size of the bank & $1.7 \%$ & $0.7 \%$ & $10.2 \%$ & $2.5 \%$ & \\
\hline Documentation required to obtain a loan & $2.4 \%$ & $4.9 \%$ & $7.6 \%$ & $4.0 \%$ & \\
\hline Staff & & $1.3 \%$ & $0.8 \%$ & $0.6 \%$ & \\
\hline Bank not requiring unrealistic guarantees & $1.2 \%$ & $11.8 \%$ & $6.8 \%$ & $5.8 \%$ & \\
\hline Something else & & & $3.4 \%$ & $0.5 \%$ & \\
\hline Don't know/No answer & $2.6 \%$ & $2.9 \%$ & $10.2 \%$ & $3.8 \%$ & \\
\hline
\end{tabular}

** statistically significant at $1 \%$; statistically significant at $5 \%$

Source: Authors' calculation 
Table 7: Clusters according to the supply management approach criteria (\% of firms in the cluster)

\begin{tabular}{|c|c|c|c|c|c|}
\hline & Cluster 1 & Cluster 2 & Cluster 3 & Total & $\begin{array}{c}\text { Chi-square } \\
\text { (p-value) }\end{array}$ \\
\hline \multicolumn{6}{|c|}{ The most important characteristic of a bank } \\
\hline Security and stability & $72.3 \%$ & $81.7 \%$ & $60.2 \%$ & $74.0 \%$ & \multirow{9}{*}{$\begin{array}{c}102.624 \\
\left(0.000^{* *}\right)\end{array}$} \\
\hline Low interest rates & $4.7 \%$ & $2.0 \%$ & $0.8 \%$ & $3.2 \%$ & \\
\hline Low commissions and fees & $6.9 \%$ & $2.3 \%$ & $4.2 \%$ & $4.8 \%$ & \\
\hline Approves the loan & $0.7 \%$ & $0.3 \%$ & $1.7 \%$ & $0.7 \%$ & \\
\hline Familiar person & $0.7 \%$ & $0.7 \%$ & $2.5 \%$ & $0.9 \%$ & \\
\hline Support for business abroad & $6.6 \%$ & $2.9 \%$ & $0.8 \%$ & $4.5 \%$ & \\
\hline Specialization for the company's industry & $3.8 \%$ & $2.6 \%$ & $16.9 \%$ & $5.2 \%$ & \\
\hline Familiar bank & $0.9 \%$ & $2.9 \%$ & $8.5 \%$ & $2.7 \%$ & \\
\hline Other & $3.3 \%$ & $4.6 \%$ & $4.2 \%$ & $3.9 \%$ & \\
\hline \multicolumn{6}{|c|}{ Major bank (where most of the services are used) } \\
\hline Bank A & $24.8 \%$ & $33.3 \%$ & $28.8 \%$ & $28.5 \%$ & \multirow{6}{*}{$\begin{array}{l}78.146 \\
(0.058)\end{array}$} \\
\hline Bank B & $11.8 \%$ & $14.7 \%$ & $13.6 \%$ & $13.1 \%$ & \\
\hline Bank C & $9.9 \%$ & $6.2 \%$ & $5.1 \%$ & $7.9 \%$ & \\
\hline Bank D & $9.5 \%$ & $9.2 \%$ & $12.7 \%$ & $9.8 \%$ & \\
\hline Other banks & $44.0 \%$ & $36.6 \%$ & $39.8 \%$ & $40.7 \%$ & \\
\hline No answer & $22.2 \%$ & $18.7 \%$ & $20.1 \%$ & $19.3 \%$ & \\
\hline \multicolumn{6}{|c|}{ Level of satisfaction with the current major bank } \\
\hline Highly satisfied & $30.3 \%$ & $26.8 \%$ & $28.0 \%$ & $28.7 \%$ & \multirow{6}{*}{$\begin{array}{l}12.877 \\
(0.231)\end{array}$} \\
\hline Mostly satisfied & $44.4 \%$ & $47.4 \%$ & $47.5 \%$ & $45.9 \%$ & \\
\hline Undecided & $18.4 \%$ & $20.9 \%$ & $16.1 \%$ & $19.0 \%$ & \\
\hline Mostly not satisfied & $2.6 \%$ & $3.6 \%$ & $3.4 \%$ & $3.1 \%$ & \\
\hline Not satisfied at all & $1.7 \%$ & & $3.4 \%$ & $1.3 \%$ & \\
\hline No answer & $2.6 \%$ & $1.3 \%$ & $1.7 \%$ & $2.0 \%$ & \\
\hline
\end{tabular}

** statistically significant at $1 \%$; statistically significant at $5 \%$

Source: Authors'calculation

In Table 7 clusters are compared according to the supply management approach criteria. Chi-squares show significant association between clusters and important characteristic of a bank $\left(\chi^{2}=102.626, p<0.000\right)$ but not in the case of the most important characteristics of the bank $\left(\chi^{2}=78.146\right.$, $\mathrm{p}=0.058$ ) nor in the case of frequency of usage of services $\left(\chi^{2}=12.877, p=0.231\right)$. It can be concluded that the level of satisfaction and frequency of usage are the same in all clusters.

\section{DISCUSSION}

Each cluster can be described by combining all the variables included in the analysis. In order to clearly indicate the difference among clusters, appropriate labels were given to the clusters.

\section{Cluster 1 - Largest-growing}

Companies in Cluster 1 have the largest average export and import ratio in the annual turnover (import 29.6\%, export
$16.1 \%$ ) and they are also the largest in terms of the annual income in the last year (10-50 million EUR). Therefore, this cluster was labelled as Largest-growing. This cluster has the highest proportion of state-owned companies, but it also consists of foreign companies (with higher turnovers). Companies in this cluster plan new employment more often than companies in other clusters, which could indicate that they have a clear growth strategy. When selecting a bank for a loan, important factors include interest rates, quickness of loan approval and a simplified method of funds withdrawal. In addition, they also demand greater security and affordable interest rates. In banking services, they want high transaction accuracy, and promptness in solving problems or requests. These companies want to ensure undisturbed functioning of business processes, especially with international partners. Therefore, banks should offer specialized services.

\section{Cluster 2 - Smallest-stagnating}

Companies in Cluster 2 have the lowest turnovers that are stagnating. They have a minimum average trade ratio with 
foreign countries (import 11\%, export 6.9\%) and the minimal annual revenue in the last year (under 0.5 million EUR). Therefore, this cluster was labelled as Smallest-stagnating. A great proportion of these companies are privately owned and established by domestic capital. They expect employment stagnation, but do not plan any layoffs. When selecting a bank for a loan, the most important factors for them are interest rates, quickness of loan approval and simple loan approval procedures. They demand that banks maintain a high degree of security, affordable interest rates, and warranties on investments. Also, they expect banking services to provide a wide spectrum of products and services, transaction accuracy and quickness in solving problems or requests. The data in this cluster have shown that most of those companies are privately owned and are mainly established by domestic investors. Thus, this cluster has the lowest number of foreign investors. The minimal annual turnover in this cluster indicates that these companies are mostly smallsized enterprises or crafts. This is also supported by the fact that they have an underdeveloped employment strategy and their plans on the increase of the number of employees are stagnating. It is important to notice that they want a wide spectrum of banking services, which makes them distinctive from the other two clusters, while the main concern for large companies (Cluster 1) is transaction accuracy.

\section{Cluster 3 -Medium-growing}

Companies in Cluster 3 are mostly medium sized in terms of annual turnover. Their turnovers show the highest growth rate of all three clusters. Therefore, this cluster was labelled as Medium-growing. They have the largest import to annual turnover ratio $(22.1 \%)$, but they also have a small export to annual turnover ratio (9.9\%). They have a yearly income between 0.5 and 10 million EUR, are mostly privately owned and are established with domestic capital. They do not plan to lay off many employees but plan to maintain the current number of employees, and a certain number of companies also plan new employments. When selecting a bank for loans, the most important factors are quick loan approval, simple procedures or warranty instruments and reasonable warranties in exchange for the loan. An ideal bank should be secure and stable, have a dedicated person for problem solving and the ability to quickly answer requests, and should guarantee the stability of savings. Desirable banking services include transaction accuracy, quick request response and problem solving (similar to Cluster 1). The main segment characteristics are domestic capital and an effort to maintain the current number of employees. When applying for loans, they prefer the quickness of loan approval and a simple procedure rather than lower interest rates. They also demand transaction accuracy, like the companies in Cluster 1.

\section{CONCLUSION}

The aim of the paper was to create and explain business customer segmentation in the Croatian banking industry using self-organizing maps. It has been shown that an easier understanding of the attribute interrelationship between the input data as a basis for decision-making can be improved by using dimensionality reduction and visualization of the multi-dimensional data on a two-dimensional map. The combination of self-organizing maps with the classical cluster analysis in the Ward technique of clustering done using Viscovery SOMLine proved to be a useful tool for cluster analysis. To our knowledge, there is no research paper that investigates segmentation of the corporate sector in the banking industry in a transition country. Thus, by examining Croatia this paper provides required finidings and cognitions. In addition, banks often use the traditional segmentation of the corporate sector, and with this research we showed the advantages of using the SOM-Ward method. The combination of different segmentation criteria with the SOM-Ward method resulted in extracting three clusters which give a detailed explanation of the corporate sector in Croatia.

Our research showed that important segmentation characteristics are based on the characteristics of the corporate sector itself (industry sector, import, export, total revenue, origin of the capital, ownership of the companies) and the given bank's characteristics (the importance of selecting a bank, rating of a bank, criteria for selection, the most important characteristics of a bank). Based on the description of each cluster, banks could create a business strategy customized to each cluster. This means that different strategies should be tailored not just according to what customers want, such as criteria for selection and the important characteristics of a bank, but also according to their characteristics, such as revenue and the industry sector they belong to. It is important to emphasize that the following segmentation criteria are shown to not be significant: the number of employees in companies, plans for employment, the level of satisfaction with the bank and the current bank selection. Market segmentation by SOM could also provide marketing experts with the ability of making a variety of different activities tailored to each segment, which enables banks to increase their profitability.

However, when using the results of our research several limitations should be taken into account, which consequently opens possibilities for future research. First, we selected our criteria based on a broad selection of criteria. However, we did not include other criteria that could be also important for the decision on the selection of a bank by business clients, such as the amount of banking provisions and the ease of use of the Internet banking sector (Assunção, 2013). Since the banking industry is experiencing the constant threat of intruders' attacks on Internet banking software (Nasri and Charfeddine, 2012), the issue of Internet security should also be taken into account. Second, in our research we purposefully included a higher percentage of large firms in our sample because of their importance for the Croatian economy. Therefore, further research in the field of market segmentation could be conducted for large, small and medium firms separately. 


\section{REFERENCES}

1. Agarwal, J., Malhotra, N. K., Bolton, R. N. 2010. A cross-national and cross-cultural approach to global market segmentation: An application using consumers' perceived service quality. Journal of International Marketing 18(3): 18-40.

2. Anderson, W.T., Cox, E.P., Fulcher, D.G. 1976. Bank Selection Decisions and Market Segmentation. Journal of Marketing 40(1): 40-45.

3. Assunção, J. 2013. Eliminating entry barriers for the provision of banking services: Evidence from 'banking correspondents' in Brazil. Journal of Banking \& Finance 37(8): 2806-2811.

4. Athanassopoulos, A. D. 2000. Customer satisfaction cues to support market segmentation and explain switching behavior. Journal of Business Research 47(3): 191-207.

5. Bloom, J.Z. 2004. Tourist market segmentation with linear and non-linear techniques. Tourism Management 25(6): 723-733.

6. Chan, K.Y., Kwong, C.K., Hu, B.Q. 2012. Market segmentation and ideal point identification for new product design using fuzzy data compression and fuzzy clustering methods. Applied Soft Computing 12(4): 1371-1378.

7. Chen, J., Bell, P. C. 2012. Implementing market segmentation using full-refund and no-refund customer returns policies in a dual-channel supply chain structure. International Journal of Production Economics 136(1): 56-66.

8. Deboeck, G., Schmitt, B. 1998. Differential Patterns in Consumer Purchase Preferences using Self-Organizing Maps: A Case Study of China, Visual Explorations in Finance: with selforganizing maps, edited by G. Deboeck, T. Kohonen, 141-156, London: Springer.

9. Denton, L., Chan, A.K.K. 1991. Bank Selection Criteria of Multiple Bank Users in Hong Kong, International Journal of Bank Marketing 9(5): 23-34.

10. Edris, T. A. 1997. Services considered important to business customers and determinants of bank selection in Kuwait: a segmentation analysis. International Journal of Bank Marketing 15(4): 126-133.

11. Ekinci, Y., Uray, N., Ulengin, F. (2014). A customer lifetime value model for the banking industry: a guide to marketing actions. European Journal of Marketing 48(3/4), Accepted for publication.

12. Garland, R. 2005. Segmenting retail banking clients. Journal of Financial Services Marketing 10: 179-191.

13. Han, J., Kamber, M. 2006. Data Mining: Concepts and Techniques. Tokyo: Morgan Kaufmann Publishers.

14. Hanafizadeh, P., Mirzazadeh, M. 2011. Visualizing market segmentation using self-organizing maps and Fuzzy Delphi method ADSL market of a telecommunication company. Expert Systems with Applications 38(1): 198-205.

15. Hung, C. Tsai, C.F. 2008. Market segmentation based on hierarchical self-organizing map for markets of multimedia on demand, Expert Systems with Applications 34(2): 780-787.

16. Jagric, T., Jagric, V. 2011. A Comparison of Growing Cell Structures Neural Networks and Linear Scoring Models in the Retail Credit Environment. Eastern European Economics 49(6): 74-96.

17. Kiang, M. Y. 2001. Extending the Kohonen self-organizing map networks for clustering analysis. Computational Statistics \& Data Analysis 38: 161-180.
18. Kiang, M.Y., Hu, M.Y., Fisher, D.M. 2006. An extended self-organizing map network for market segmentation-a telecommunication example. Decision Support Systems 42(1): 36-47.

19. Kim, J. N., Grunig, J. E. 2011. Problem solving and communicative action: A situational theory of problem solving. Journal of Communication 61(1): 120-149.

20. Kohonen, T. 1995. Self-organizing maps. Berlin: Springer-Verlag.

21. Kotler, P., Armstrong, G., Saunders, J. \& Wong, V. 2001. Principles of Marketing, Prentice Hall, Harlow.

22. Kumar, P. R., Ravi, V. 2007. Bankruptcy prediction in banks and firms via statistical and intelligent techniques - A review. European Journal of Operational Research 180: 1-28.

23. Kuo, R.J., Ho, L.M., Hu, C.M. 2002. Integration of self-organizing feature map and K-means algorithm for market segmentation. Computers \& Operations Research 29(11): 1475-1493.

24. Laroche, M., Rosenblatt, J.A., Manning, T. 1986. Services Used and Factors Considered Important in Selecting a Bank: An Investigation across Diverse Demographic Segments, International Journal of Bank Marketing 4(1): 35 - 55.

25. Lee, K., Booth, D., Pervaiz, A. 2005. A comparison of supervised and unsupervised neural networks in predicting bankruptcy of Korean firms. Expert Systems with Applications, 2: 1-16.

26. Machauer, A., Morgner, S. 2001. Segmentation of bank clients by expected benefits and attitudes, International Journal of Bank Marketing, 19(1): 6-18.

27. Mäenpää, K. 2006. Clustering the consumers on the basis of their perceptions of the Internet banking services. Internet Research, 16(3): 304-322.

28. Mangiameli, P., Chen, S. K., West, D. 1996. A comparison of SOM neural network and hierarchical clustering methods. European Journal of Operational Research 93(2): 402-417.

29. Nasri, W., Charfeddine, L. 2012. Factors affecting the adoption of Internet banking in Tunisia: An integration theory of acceptance model and theory of planned behavior. The Journal of High Technology Management Research 23(1):1-14.

30. Patsiotis, A. G., Hughes, T., Webber, D. J. 2012. Adopters and non-adopters of internet banking: a segmentation study. International Journal of Bank Marketing 30(1): 20-42.

31. Shocker, A. D., Ben-Akiva, M., Boccara, B., Nedungadi, P. 1991. Consideration set influences on consumer decision-making and choice: Issues, models, and suggestions. Marketing letters 2(3): 181-197.

32. Sponer, M. 2012. Segmentation of corporate clients in a bank, Masaryk University, Brno, Czeck Republik.

33. Turnbull, P. W., Gibbs, M. L. 1987. Marketing bank services to corporate customers: the importance of relationships. International Journal of Bank Marketing 5(1): 19-26.

34. Vellido, A., Lisboa, P.J.G., Meehan, K. 1999. Segmentation of the on-line shopping market using neural networks. Expert Systems with Applications, 17(4): 303-314.

35. Venkatesh, R. 2011. New Parameters in Market SegmentationEthnic Marketing is the Key. Advances In Management 4(11): 15-19.

36. Watson, H.J., Wixom, B.H. 2007. The Current State of Business Intelligence, Computer, 40(9): 96-99.

37. Wedel, M., Kamakura, W. 2003. Market Segmentation: Conceptual and Methodological Foundations, Kluwer Academic Publishers, Norwell. 